\title{
How Powerful is Unannounced, Sterilized Foreign
}

\author{
Exchange Intervention?
}

\author{
Alain Naef * \\ Jacob P. Weber ${ }^{\dagger}$
}

October 6, 2022

\begin{abstract}
Though most central banks actively intervene on the foreign exchange market, the literature offers mixed evidence on their effectiveness: particularly for unannounced interventions. We use new, declassified data from the archives of the Bank of England and the institutional features of the Bretton Woods era to estimate the effects of intervention on the exchange rate. We find that a purchase of pounds equivalent to $1 \%$ of the money supply causes a statistically significant, $4-5$ basis point appreciation in the pound.
\end{abstract}

${ }^{*}$ Banque de France. Email: alain.naef@banque-france.fr

†Department of Economics, UC Berkeley. Email: jacob_weber@berkeley.edu

We thank Bill Allen, Michael Bordo, Barry Eichengreen, Galina Hale, Walter Jansson, Gaurav Manek, Peter McCrory, Todd Messer, Emi Nakamura, Christina Romer, David Romer, Jón Steinsson, and seminar participants in the Berkeley Economic History Lunch and Banque de France seminar for valuable comments and discussion. We are especially grateful to Tobias Heiland for agreeing to discuss this paper. The views expressed in this paper do not represent the opinion of the Banque de France or the Eurosystem.

JEL Codes: F3, N2.

Keywords: Monetary Policy, Foreign Exchange Markets, Bretton Woods System. 


\section{Introduction}

Most developing and many advanced economies intervene in foreign exchange markets to manage volatility and unwanted exchange rate movements. Many central banks both sterilize their interventions and conduct them secretly, meaning without any announcement beforehand or acknowledgement after the fact. ${ }^{1}$ Using recently-collected data on the Bank of England's daily operations during the Bretton Woods era, we conduct a new analysis of such unannounced, never-acknowledged sterilized intervention and find statistically significant effects on the level of the exchange rate.

Our analysis informs an ongoing debate regarding whether sterilized foreign exchange intervention could meaningfully impact the exchange rate. In this context, "sterilized intervention" means market operations undertaken to influence the exchange rate while leaving the monetary base unchanged. This usually takes the form of a paired transaction in which the central bank buys (sells) domestic currency in foreign exchange markets while simultaneously selling (buying) domestic currency bonds. Policymakers generally believe that unsterilized intervention could work through impacting relative interest rates, and that public, sterilized intervention may work through a signaling channel. With sterilized, secret intervention these channels will be absent or muted, and policymakers exhibit less agreement on whether intervention may be effective in this context. ${ }^{2}$

Despite this, many policymakers intervene in secret, including e.g. developing economies in Asia (Fratzscher et al., 2019). Additionally Chamon et al. (2019) report that despite officially committing to floating regimes and inflation targeting, many countries in Latin America use foreign exchange intervention as part of their policy mix. The IMF has also included foreign exchange intervention as part of its new institutional policy framework, ensuring that the debate on efficacy will remain relevant.

The academic literature on intervention surveyed in e.g. Sarno and Taylor (2001) and

\footnotetext{
${ }^{1}$ From a recent survey of 22 "Emerging Market Economy" central banks, 17 reported "Never" or "Rarely" pre-announcing their intervention; when asked if they published data after the fact, 7 reported never publishing data at all and only 9 reported publishing data at a greater-than-monthly frequency (Mohanty and Berger, 2013); separately, most reported routinely sterilizing their interventions.

${ }^{2}$ When surveyed, most central bankers agree that the signaling channel of sterilized foreign exchange intervention is "effective" while exhibiting less agreement on other channels (Mohanty and Berger, 2013).
} 
Neely (2008) focuses disproportionately on the few central banks that intervene publicly and publish their intervention data. Even when circumstances have allowed for the study of other central banks, it is not always clear whether the operations were really secret or promptly sterilized. ${ }^{3}$ This renders disentangling the channels at play challenging. Finally, even with access to quality data, all studies of the effects of intervention must grapple with the issue of endogeneity, as intervention is far from randomly assigned. See Fratzscher et al. (2019) for a recent discussion of both issues. Recent work has used high-frequency, intra-day data to overcome some of these issues and identifies the effects of intervention with event study or regression discontinuity approaches (Fatum and King, 2005; Menkhoff, 2010; Kuersteiner et al., 2018). In our setting, such data are not available; we therefore rely on alternative methods and daily data.

By studying the Bank of England, we contribute a case study of a central bank that intervened frequently (on over $80 \%$ of trading days in sample), sterilized immediately, and operated with a high degree of secrecy. Relative to previous studies on the Bank of England (Naef, 2019, 2021) reporting mixed evidence for effectiveness from correlations and event-studies, this paper presents causal point estimates of the effect of sterilized foreign exchange intervention on the exchange rate. We leverage the institutional setting of the Bretton Woods era to motivate two approaches to identification: an instrumental variables (IV) approach which forms the benchmark analysis in the paper, and a "Policy Rule" approach presented in online Appendix B. The latter proceeds by estimating a rule for determining the quantity of intervention normally conducted by the Bank of England, and treating deviation from it as a shock to intervention on days when the Bank of England was closed for a UK-specific Banking Holiday. The point estimates of these two independent approaches yield reassuringly similar results.

To understand how both approaches deal with endogeneity, we appeal to a reducedform model of the portfolio balance channel, as this theory traditionally garnered the most

\footnotetext{
${ }^{3}$ Examples include Fratzscher et al. (2019), which includes 23 non-public datasets on daily intervention and likely includes many secret interventions (the authors found news coverage for only half of their intervention episodes) and which the contributing central banks affirmed were sterilized. Some recent high-frequency studies on secret, intraday data on intervention in the market for the Czech koruna include Dominguez et al. (2013), who look at sales of reserves, and Scalia (2008), who studies sterilized interventions without observing quantities, making inference instead based on intervention dates.
} 
attention as an explanation for the efficacy of sterilized intervention absent information effects. ${ }^{4}$ The model informs our regression specifications and disciplines our discussion of identification issues. We note that ordinary least squares (OLS) estimates of the effects of intervention will be biased if central banks "lean against the wind." For example, if the Bank of England attempted to strengthen the pound whenever it was weakening due to some fundamental shock, this would bias OLS estimates towards finding intervention unproductive (or even counterproductive). Both approaches yield results consistent with such a bias, despite relying on completely different identification assumptions.

Our IV approach takes advantage of the Bank of England's explicit exchange rate target during Bretton Woods, and uses the lagged distance of the exchange rate from target as an instrument for intervention. The motivation for this instrument is that the dealers working for the Bank of England, who were charged with intervening, may have been quicker to act if the exchange rate closed further from target the day before. The identifying assumption is that the level of the exchange rate the day before does not impact the growth rate of the exchange rate, except through the (secret) actions of the central bank. We motivate this by noting that if our assumption did not hold, and the level of the exchange rate was useful for forecasting its growth rate, then market participants consistently "left money on the table" in a large and liquid market. Point estimates obtained from this approach are precisely estimated and robust to variations in specification of the instrument, set of controls, and time period of estimation. This identification assumption may not hold if there is mean reversion in fundamental shocks to the exchange rate, and the hope is that such mean reversion is small. ${ }^{5}$

We are not the first to estimate the effects of sterilized foreign exchange intervention. Menkhoff, Rieth, and Stöhr (2020) use a structural vector autoregressive model with external instruments to identify the effects of the Bank of Japan's pre-announced

\footnotetext{
${ }^{4}$ We avoid framing our results as showing a portfolio balance channel in recognition of e.g. a market microstructure channel or other channels which might operate independently of the signaling channel, and which our empirical analysis will not rule out.

${ }^{5}$ Online Appendix $\mathrm{C}$ presents a simple theoretical model where the exclusion restriction nearly holds if unobserved, fundamental shocks to the level of the exchange rate are almost a random walk; online Appendix D explores this issue quantitatively, establishing through simulation that small amounts of mean reversion are unlikely to be driving our results.
} 
interventions. We use data on interventions that were never made public and take different approaches to identification. Several recent papers present estimates using readilyavailable, low-frequency proxies for intervention. ${ }^{6}$ A large event study literature evaluates the effect of intervention on a number of explicit success criteria, such as the direction of the exchange rate, reporting mixed results. For example, Fratzscher et al. (2019) finds that intervention is effective in up to $80 \%$ of cases, while Bordo et al. (2012) argue that the success rate for US interventions was historically no better than random.

This paper contributes to this literature by establishing the presence of nontrivial effects of sterilized intervention absent a significant signaling channel. This finding at least partially rationalizes the choice of many central banks to conduct intervention secretly.

\section{Historical and Institutional Context}

The Bretton Woods system of pegged exchange rates lasted from 1944 to 1971, but our analysis begins in January of 1952 when the Bank of England reopened the foreign exchange market. This setting has three important features for our analysis: the Bank of England was charged with managing a clear exchange rate target; the sterilization of the foreign exchange operations we study was automatic; and interventions were secret.

In the system, the dollar was fixed to gold at $\$ 35$ an ounce and all other currencies were pegged to the dollar with a band of plus or minus $2 \%$. The pound was fixed at the official price of $\$ 2.80$ per pound between 1949 and 1967 , and at $\$ 2.40$ per pound between 1967 and the collapse of the system when President Nixon closed the "gold window" on August 15th, 1971. We use the pound/dollar exchange rate, and Figure 1 plots the exchange rate and target over time in these units.

Another key feature of our setting is that the interventions we study were systematically sterilized, as they were conducted through the Exchange Equalisation Account (EEA); Howson (1980) and more recently Allen (2019) establish that sterilization was a

\footnotetext{
${ }^{6}$ See e.g. Blanchard, Adler, and Filho (2015), who use changes in foreign exchange reserves observed at a quarterly frequency; Daude, Yeyati, and Nagengast (2016) who use changes in the ratio of reserves to M2 at a monthly frequency; and Adler, Lisack, and Mano (2019), who use changes in the central bank balance sheet at a monthly frequency.
} 
built-in feature of the EEA. By design, any operation of the EEA had a counterparty in UK Treasury bills, leading to automatic sterilization (note that the EEA is a government body technically independent from the Bank of England, which only manages the EEA). This makes us confident that we are indeed estimating effects of sterilized intervention and not simply picking up effects resulting from changes in the money supply.

Our setting's last notable feature is that all interventions studied were conducted in secret, meaning that the Bank of England did not communicate their daily intervention operations or make public the data at any point. ${ }^{7}$ A natural question is whether these operations were secret in practice, as the Bank of England's counterparties (a small number of private banks) knew when it engaged in foreign exchange transactions. We argue that intervention was likely secret for three reasons. First, not all of the central bank's foreign exchange transactions were associated with intervention, making it difficult in practice for counterparties to determine the bank's intentions at short horizons. The Bank of England, nationalized in 1946, retained many private customers (including other central banks) and frequently engaged in "customer operations" in addition to the intervention we study. These operations were substantial: on approximately $40 \%$ of our observed intervention days, the bank was also engaged in customer operations. This would have made it difficult to disentangle the Bank's intention from its observed purchases and sales.

Second, the Bank of England outsourced some of its intervention to other central banks, reflecting the global nature of the foreign exchange market. Although most intervention was conducted in the London spot market, the Bank could request that the Federal Reserve, for example, intervene in the New York market and frequently did so (on just over $15 \%$ of all trading days).

Finally, anecdotal evidence confirms that secrecy was a goal from an early date, and that the Bank of England's dealers believed themselves to have been successful in this goal. In 1936, the senior official at the Bank of England in charge of foreign exchange matters, Harry Arthur Siepmann, noted that:

Experience has enabled some progress to be made in concealing or advertising

\footnotetext{
${ }^{7}$ Public announcements accompanied interventions beginning in the 1980s.
} 
the presence of the 'control', and this has led to masked intervention being resorted to more frequently and successfully. It is sometimes surprising to find how wide of the mark are the press reports of the EEA activity, as when on 6 April we bought nearly Fr.200 million but were reported by the financial news next morning as having "retired from the market soon after opening"... It is equally clear that, whatever precautions are taken, the presence of the 'control' cannot, as a general rule, escape observation, though guesses may be good or bad about the extent of its daily operations. ${ }^{8}$

Thus while markets understood the Bank intervened, day-to-day variations were difficult to discern. By the 1950s, "masked" intervention was the rule, and secrecy an established policy goal. In a 1956 communication with the New York Fed, Roy Bridge, head dealer at the Bank of England, explained his strategy: 'I shall ask you to go into the market after lunch. ... Don't go before lunch. I thought it wise to change tactics a bit. It is a good thing. ${ }^{9}$ In short, the Bank took pains to conceal its intervention, and believed these efforts to have been successful. ${ }^{10}$

\section{New Archival Data}

We analyze a new, daily time series on the foreign exchange operations of the Bank of England taken from confidential reports sent from the Bank of England to the Treasury, which discriminates between "customer" operations and intervention meant to influence exchange rates (Naef, 2019, 2021). Figure 2 presents the daily series on intervention, deflated by UK M0. While the majority of this intervention was conducted directly by the Bank of England in the London pound/dollar spot market, the measure also includes intervention conducted by other central banks on the Bank of England's behalf in offshore markets. Note the sheer frequency of intervention: on approximately $83.3 \%$ of the trading days the Bank of England intervenes in the spot market. For comparison, Fratzscher et al.

\footnotetext{
${ }^{8}$ Archives of the Bank of England, Harry Arthur Siepmann papers, reference C14/1, 1936.

${ }^{9}$ Telephone conversation with Mr. Bridge, Bank of England at 11:15 am, H. L. Sanford to file, 10 August 1956, New York, Archives of the Federal Reserve, box 617015.

${ }^{10}$ For more on the Bank of England intervention strategies, see Naef (2021).
} 
(2019) find in a sample of 33 central banks observed from 1995-2011 an average frequency of intervention of $19.1 \%$ of trading days. Data on exchange rates comes from Accominotti, Cen, Chambers, and Marsh (2019). See Table 1 for descriptive statistics. We also include various interest rate controls in some specifications, documented in online Appendix E. ${ }^{11}$

\section{$4 \quad$ IV Estimates}

Let $e_{t}$ be the pound/dollar exchange rate at the end of day $t$, plotted in Figure 1, and let $Q_{t}$ be intervention undertaken to appreciate the pound defined as dollar sales as a share of UK M0, plotted in Figure 2. A naive attempt to estimate the marginal effect of intervention on the exchange rate would be to estimate the following via OLS:

$$
\ln e_{t}-\ln e_{t-1}=\beta_{0}+\beta_{1} Q_{t}+\epsilon_{t}
$$

where $\epsilon_{t}$ is an (unobserved) shock to growth in the exchange rate. Conventional wisdom suggests $\beta_{1}$ should be negative, as a sale of dollars (and purchase of pounds) should decrease the value of the dollar relative to the pound. But if $Q_{t}$ is not randomly assigned, and the central bank "leans against the wind," estimates of $\beta_{1}$ will be biased upward.

To surmount this, we instrument for endogenous $Q_{t}$ with the square of the distance from the exchange rate target at time $t-1$, which we allow to take on negative values when below target. Formally, the distance instrument $Z_{t} \equiv\left(\ln e_{t-1}-\ln e_{t-1}^{\text {target }}\right)^{2} \times \operatorname{sign}\left(\ln e_{t-1}-\right.$ $\ln e_{t-1}^{\text {target }}$ ), where the target is time-varying only because of the devaluation in sample (note changes in the lagged, log level of the exchange rate drive the variation in this instrument so using $Z_{t}=\ln e_{t-1}$ yields very similar results; see the tables in Appendix A.2). We motivate this instrument by arguing that if yesterday's market closed far from the target, then regardless of today's developments the dealers may intervene more aggressively.

Formally, exclusion requires that our instrument only impacts the growth of the exchange rate through its effect on the actions of the Bank of England, which were not

\footnotetext{
${ }^{11}$ We also rely on gold reserve data from the Bank of England which we potentially allow to influence our forecasting and policy rules in Section B. An earlier draft explored lagged gold reserves as an instrument but the results were uninformative due to low power in the first stage; see Naef and Weber (2021).
} 
observed directly by market participants at this time. To evaluate this, consider what it would mean for our exclusion assumption to not hold. This would imply that the level of the exchange rate was useful for forecasting its growth rate at very short horizons, and thus that traders consistently left money on the table in a large and liquid market.

A concern is that there may be predictable mean reversion at short horizons independent of the actions of the central bank, which would violate the exclusion restriction. Online Appendix C illustrates this concern by analyzing a simple first-order approximation of a reduced-form portfolio balance channel model, noting that mean reversion in (unobserved) fundamental shocks to the exchange rate violates the exclusion restriction. However, we note that exclusion will nearly hold if the shocks to the exchange rate follow a nearly random walk (i.e. a near unit root, stationary first-order autoregressive process).

Is this assumption valid? In the wake of Meese and Rogoff (1983), subsequent work documented that while exchange rates appeared well-modelled by a random walk, some mean reversion is detectable at longer horizons (Rossi, 2013). However, at the daily frequency considered here, the quantity of mean reversion consistent with long run estimates is quite small. Thus, while any deviations from a unit root process would violate our identification assumption and bias our estimates of $\beta_{1}$ downward, plausibly-small amounts of mean reversion are unlikely to be driving our results (Online Appendix D establishes this through simulations and discusses this issue in greater detail).

Table 2 presents estimates of $\beta_{1}$ in equation (1) comparing OLS to IV estimates. The results accord well with theory. When we estimate (1) by OLS, we find results consistent with severe upward bias as the coefficient is positive and significant, the opposite of what theory and the intuition of generations of central bankers suggests. However, when using the distance instrument, the sign flips, becoming negative and of reasonable magnitude. The interpretation of each coefficient is the increase (in percentage points) in the exchange rate that would result from a sale of dollars/purchase of pounds equivalent to $1 \%$ of British M0: the IV result suggests an effect of negative 10 basis points. Table 3 presents the first stage to verify the economic intuition. The first stage is strong and signs are as expected: when the pound is "too strong" relative to target yesterday, the Bank of England moved 
to weaken it (and vice versa when the pound was too weak).

We also consider changes to time period of estimation, estimating regressions for the pre-devaluation and post-devaluation periods separately, as well as a sample dropping the entire month of the devaluation, and finally a sample dropping data prior to 1959 as an important liberalization in UK capital markets occurred in late December 1958 when current account convertibility was restored as a consequence of the European Monetary Agreement. While the capital account was still not completely liberated, the policy meant much larger capital flows in and out of the UK. This last exercise is particularly useful for understanding whether the presence of greater capital controls in the 1950s is driving our results, which does not appear to be the case.

\subsection{Robustness Checks and Comparision to the Literature}

Online Appendix A considers several robustness checks. Appendix A.1 adds controls to equation (1), guided by the model in Online Appendix C, while Appendix A.2 considers changing the instrument to use the lagged, log level of the exchange rate. ${ }^{12}$ The results are consistent. Appendix A.3 reports results measuring intervention as dollar sales, which also eases comparision with the literature. Those results suggest a sale of $\$ 1 \mathrm{bn}$ USD appreciates the pound by 1.2 percentage points, which compares favorably with other estimates; Arango-Lozano, Menkhoff, Rodríguez-Novoa, and Villamizar-Villegas (2020) report an average effect of one percentage point in a meta study of 74 empirical studies.

Finally, Appendix B estimates the effect of intervention by first estimating a policy rule for intervention and treating deviations driven by UK-specific bank holiday's (when the Bank of England was closed and did not intervene much) as shocks to intervention. The point estimates are similar to those in the IV regressions above.

While the results in Table 2 range from estimated effects of $6-17$ basis points, our preferred conclusion of an effect of 4-5 basis points stems from consideration of the large standard errors in that table and the estimates in Appendices A.1 and B, which are generally more precise (see e.g. Table 4, Column 4).

\footnotetext{
${ }^{12}$ The lagged, signed, squared distance from target instrument is our headline result as it has a stronger first-stage.
} 


\section{Conclusion}

This paper established the presence of nontrivial effects of sterilized intervention even absent a significant signaling channel. Our results suggest that a sterilized, unannounced sale of dollars equivalent to $1 \%$ of UK M0 causes a 4-5 basis point appreciation of the pound. Given that the median absolute change in the exchange rate was 2.2 basis points during this period, our estimates are consistent with the view that the Bank of England's interventions were useful in offsetting day-to-day fluctuations in the exchange rate.

We took two approaches to identification to obtain these results. The first used the lagged, squared distance from target as an instrument for intervention, which requires the exclusion restriction that the level of the exchange rate is not useful for forecasting it's own growth rate except through its effects on the (secret) actions of the central bank. Since this would be violated by even a small quantity of mean reversion in the exchange rate, which would bias our results downward, we also took a second approach which treated deviations from an estimated policy rule for intervention as shocks. We showed that it was important to restrict our attention to shocks which occurred during holidays, when we know that deviation from normal behavior was due to the central bank being closed, and that doing so resulted in point estimates consistent with our IV regressions.

Jointly, these results suggest the modest but economically significant effects on the level of the exchange rate which we report above.

While the context of the Bank of England during Bretton Woods is different from many central banks today, our results remain relevant to modern policymakers. Many modern central banks manage exchange rate pegs, even if their bands are often broader than those studied here, and intervene in foreign exchange markets. Our results at least partially rationalize the decision of many central banks to both intervene in secret and sterilize their interventions by demonstrating that such interventions can still have economically significant effects on the exchange rate. Our use of historical data affords us a relatively rare opportunity to study the track record of systematic, secret, sterilized intervention over a long period of time, confident in the knowledge that the data has not been manipulated prior to publication or selectively provided. 


\section{References}

Accominotti, O., J. Cen, D. Chambers, and I. W. Marsh (2019). Currency regimes and the carry trade.

Adler, G., N. Lisack, and R. C. Mano (2019). Unveiling the effects of foreign exchange intervention: A panel approach. Emerging Markets Review 40, 100620.

Ahrens, A., C. B. Hansen, and M. E. Schaffer (2020). lassopack: Model selection and prediction with regularized regression in stata. The Stata Journal 20(1), 176-235.

Allen, W. A. (2019, February). The Bank of England and the Government Debt: Operations in the Gilt-Edged Market, 1928-1972. New York: Cambridge University Press.

Arango-Lozano, L., L. Menkhoff, D. Rodríguez-Novoa, and M. Villamizar-Villegas (2020). The effectiveness of fx interventions: A meta-analysis. Journal of Financial Stability, 100794.

Bessec, M. (2003). Mean-reversion vs. adjustment to ppp: the two regimes of exchange rate dynamics under the ems, 1979-1998. Economic Modelling 20(1), 141-164.

Blanchard, O., G. Adler, and I. d. C. Filho (2015, July). Can Foreign Exchange Intervention Stem Exchange Rate Pressures from Global Capital Flow Shocks? Working Paper 21427, National Bureau of Economic Research.

Bordo, M. D., O. F. Humpage, and A. J. Schwartz (2012). The Federal Reserve as an Informed Foreign Exchange Trader: 1973-1995. International Journal of Central Banking.

Chamon, M., D. J. Hofman, N. E. Magud, and A. M. Werner (2019). Foreign exchange intervention in inflation targeters in Latin America. International Monetary Fund.

Cushman, D. O. (2007). A portfolio balance approach to the canadian-us exchange rate. Review of Financial Economics 16(3), 305-320. 
Daude, C., E. L. Yeyati, and A. J. Nagengast (2016). On the effectiveness of exchange rate interventions in emerging markets. Journal of International Money and Finance 64, $239-261$.

Dominguez, K. M., R. Fatum, and P. Vacek (2013). Do sales of foreign exchange reserves lead to currency appreciation? Journal of Money, Credit and Banking 45(5), 867-890.

Fatum, R. and M. R. King (2005). Rules versus discretion in foreign exchange intervention: evidence from official bank of canada high-frequency data.

Forrest, C. (2010). The Bank of England 1950s to 1979. Cambridge University Press, Cambridge.

Frankel, J. (1984). Tests of monetary and portfolio balance models of exchange rate determination. Exchange rate theory and practice (University of Chicago Press, Chicago).

Fratzscher, M., O. Gloede, L. Menkhoff, L. Sarno, and T. Stöhr (2019). When Is Foreign Exchange Intervention Effective? Evidence from 33 Countries. American Economic Journal: Macroeconomics.

Gabaix, X. and M. Maggiori (2015, August). International Liquidity and Exchange Rate Dynamics. The Quarterly Journal of Economics 130(3), 1369-1420.

Howson, S. (1980). Sterling's managed float: the operations of the exchange equalisation account, 1932-39. International Finance Section, Department of Economics, Princeton University.

Krugman, P., M. Obstfeld, and M. Melitz (2015). International economics: Theories and policy.

Kuersteiner, G. M., D. C. Phillips, and M. Villamizar-Villegas (2018, July). Effective sterilized foreign exchange intervention? Evidence from a rule-based policy. Journal of International Economics 113, 118-138. 
Medeiros, M. C. and E. F. Mendes (2016). l1-regularization of high-dimensional timeseries models with non-gaussian and heteroskedastic errors. Journal of Econometrics $191(1), 255-271$.

Meese, R. A. and K. Rogoff (1983). Empirical exchange rate models of the seventies: Do they fit out of sample? Journal of international economics 14(1-2), 3-24.

Menkhoff, L. (2010). High-frequency analysis of foreign exchange interventions: what do we learn? Journal of Economic Surveys 24(1), 85-112.

Menkhoff, L., M. Rieth, and T. Stöhr $(2020,03)$. The Dynamic Impact of FX Interventions on Financial Markets. The Review of Economics and Statistics, 1-45.

Mohanty, M. S. and B.-e. Berger (2013, October). Central Bank Views on Foreign Exchange Intervention. No. 73.

Murray, C. J. and D. H. Papell (2002). The purchasing power parity persistence paradigm. Journal of International Economics 56(1), 1-19.

Naef, A. (2019). Blowing against the Wind? A Narrative Approach to Central Bank Foreign Exchange Intervention. University of California, Berkeley Mimeo.

Naef, A. (2021). Dirty float or clean intervention? the bank of england in the foreign exchange market. European Review of Economic History 25(1), 180-201.

Naef, A. and J. P. Weber (2021). How powerful is unannounced, sterilized foreign exchange intervention? Technical report.

Neely, C. J. (2008, February). Central bank authorities' beliefs about foreign exchange intervention. Journal of International Money and Finance 27(1), 1-25.

Rossi, B. (2013). Exchange rate predictability. Journal of economic literature 51(4), $1063-1119$.

Sarno, L. and M. P. Taylor (2001). Official Intervention in the Foreign Exchange Market: is it Effective and, if so, How Does it Work? Journal of Economic Literature 39(3), $839-868$. 
Scalia, A. (2008). Is foreign exchange intervention effective? some microanalytical evidence from the czech republic. Journal of International Money and Finance 27(4), $529-546$.

Sweeney, R. J. (2006). Mean reversion in g-10 nominal exchange rates. Journal of Financial and Quantitative Analysis 41(3), 685-708.

Taylor, M. P. and D. A. Peel (2000). Nonlinear adjustment, long-run equilibrium and exchange rate fundamentals. Journal of international Money and Finance 19(1), 3353. 
Table 1: Descriptive Statistics for Key Variables [1952-1971]

\begin{tabular}{|c|c|c|c|c|c|}
\hline & Observations & Mean & Standard Deviation & Minimum & Maximum \\
\hline Percent Growth in the Exchange Rate: $\left(\ln e_{t}-\ln e_{t-1}\right) \times 100$ & 5,244 & $\overline{-3.64 \mathrm{e}-06}$ & 0.0510 & -0.891 & 0.865 \\
\hline Percent Distance from Target: $\left(\ln e_{t-1}-\ln e_{t-1}^{\text {target }}\right) \times 100$ & 5,244 & 0.00133 & 0.399 & -0.959 & 1.39 \\
\hline Dollar Sales (in millions USD) & 5,245 & -3.09 & 33.6 & -316 & 1,232 \\
\hline Dollar Sales as a Percentage of UK M0: $Q_{t} \times 100$ & 5,245 & -0.0345 & 0.373 & -3.78 & 12.8 \\
\hline
\end{tabular}

Notes: Summary statistics for daily observations from 1952 to 1971 which exclude the first trading day after the devaluation (i.e. the same sample as Columns 1 and 2 of Table 2). Note dollar sales takes on negative values when the Bank of England purchases dollars. The variable $Q_{t}$ comes from converting dollar sales into pounds (using the exchange rate target) and dividing by the previous month's value for UK M0. 
Table 2: Effect of Intervention on the Change in the Exchange Rate by Subsample [1952-1971]

\begin{tabular}{|c|c|c|c|c|c|c|}
\hline & \multirow{3}{*}{ 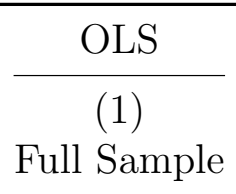 } & \multicolumn{5}{|c|}{$\mathrm{IV}$} \\
\hline & & $(2)$ & $(3)$ & $(4)$ & $(5)$ & (6) \\
\hline & & Full Sample & Pre-Devaluation & Post-Devaluation & Drop Nov. '67 & After 1958 \\
\hline Intervention & $\begin{array}{c}0.02^{* * *} \\
(0.01)\end{array}$ & $\begin{array}{c}-0.10^{* * *} \\
(0.03)\end{array}$ & $\begin{array}{c}-0.06^{* * *} \\
(0.02)\end{array}$ & $\begin{array}{l}-0.17^{*} \\
(0.07) \\
\end{array}$ & $\begin{array}{c}-0.13^{* * *} \\
(0.04)\end{array}$ & $\begin{array}{c}-0.10^{* *} \\
(0.03) \\
\end{array}$ \\
\hline Observations & 5244 & 5244 & 4278 & 966 & 5224 & 3277 \\
\hline
\end{tabular}

Notes: Heteroskedasticity-robust standard errors in parentheses. The dependent variable is the log growth in the value of the dollar relative to the pound, and "Intervention" is the daily quantity of dollar sales by the Bank of England (divided by UK M0) undertaken to appreciate the pound. Columns (1) and (2) present OLS and IV estimates of the effects of intervention, demonstrating the bias in OLS and suggesting that an intervention equivalent to $1 \%$ of UK M0 appreciates the pound by 10 basis points. Columns (3)-(6) present IV estimates for subsamples, where (5) drops the entire month containing the devaluation (November of 1967) and (6) keeps only the period after an important liberalization in UK capital markets in 1958 when current account convertibility was restored as a consequence of the European Monetary Agreement. While the capital account was not completely liberated, the policy meant much larger capital flows in and out of the UK. All regressions include day-of-week, month and year dummies and drop the first trading day after the November 1967 devaluation.

Stars indicate: ${ }^{*} p<0.05,{ }^{* *} p<0.01$, and ${ }^{* * *} p<0.001$

Table 3: First Stage Regressions: Effect on Intervention (Dollar Sales) by Subsample

\begin{tabular}{lccccc}
\hline & $(1)$ & $(2)$ & $(3)$ & $(4)$ & $(5)$ \\
& Full Sample & Pre-Devaluation & Post-Devaluation & Drop Nov. '67 & After 1958 \\
\hline Lagged, Squared Distance from Target & $0.33^{* * *}$ & $0.26^{* * *}$ & $0.49^{* * *}$ & $0.29^{* * *}$ & $0.48^{* * *}$ \\
& $(0.04)$ & $(0.03)$ & $(0.07)$ & $(0.03)$ & $(0.06)$ \\
Constant & $-0.03^{* * *}$ & -0.00 & $-0.18^{* * *}$ & $-0.03^{* * *}$ & $-0.06^{* * *}$ \\
& $(0.01)$ & $(0.00)$ & $(0.02)$ & $(0.00)$ & $(0.01)$ \\
\hline Observations & 5244 & 4278 & 966 & 5224 & 3277 \\
$R^{2}$ & 0.041 & 0.028 & 0.084 & 0.040 & 0.051 \\
F & 90.47 & 59.84 & 45.29 & 103.50 & 67.39 \\
& & & & & \\
\hline
\end{tabular}

Notes: Heteroskedasticity-robust standard errors in parentheses. The dependent variable is the daily quantity of intervention (measured as dollar sales divided by UK M0). The signs confirm the economic intuition underlying the relevance assumption: when the lagged distance from target instrument is positive, the pound is "too weak" relative to target and the Bank of England acts to strengthen it. All regressions drop the first trading day after the November 1967 devaluation. Stars indicate: ${ }^{*} p<0.05,{ }^{* *} p<0.01$, and ${ }^{* * *} p<0.001$ 


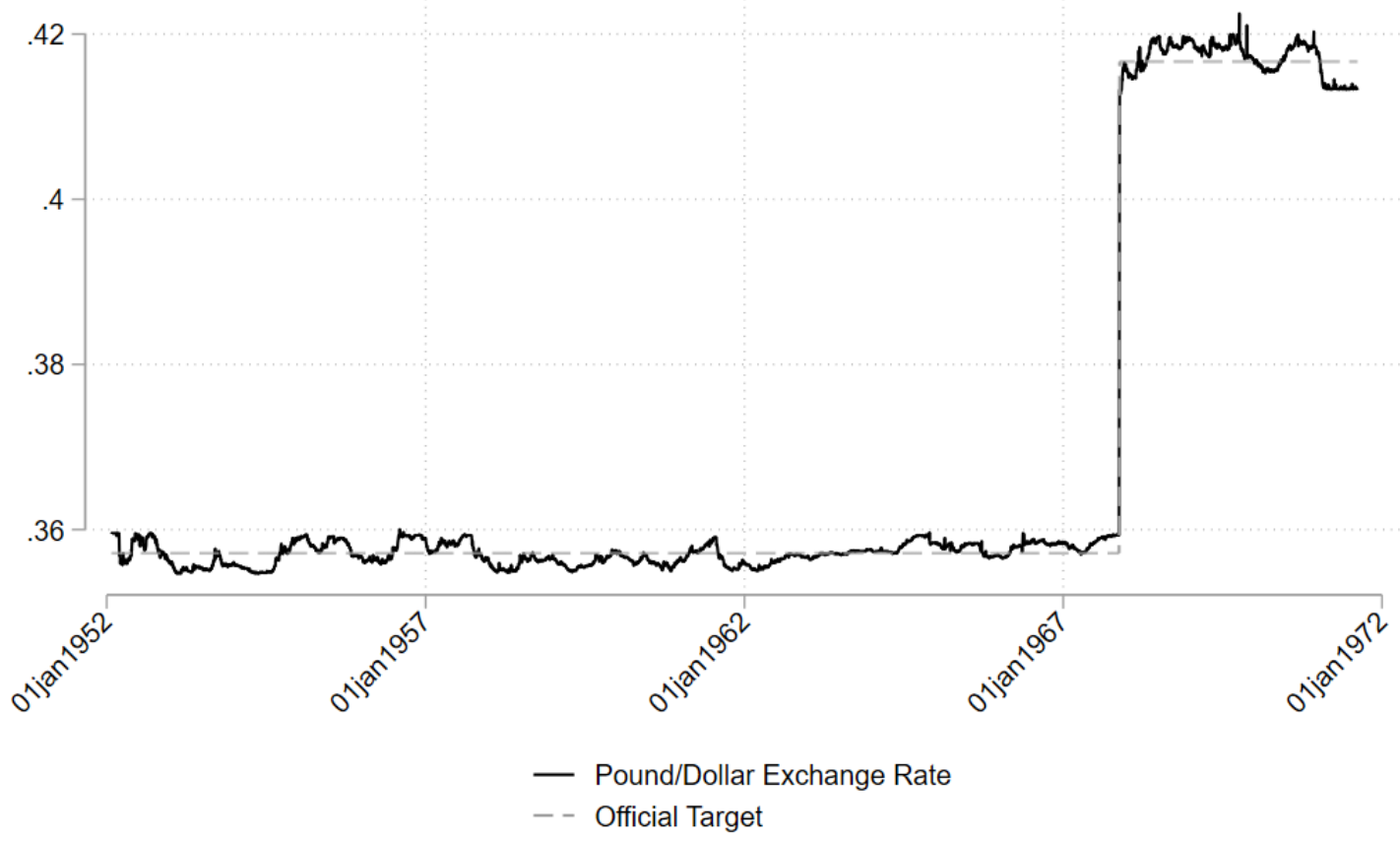

Figure 1: Above, the Pound/Dollar exchange rate is plotted over time. Note the devaluation of the pound in late November of 1967. See text for source.

Intervention over Time: Sales of Dollars as a \% of M0

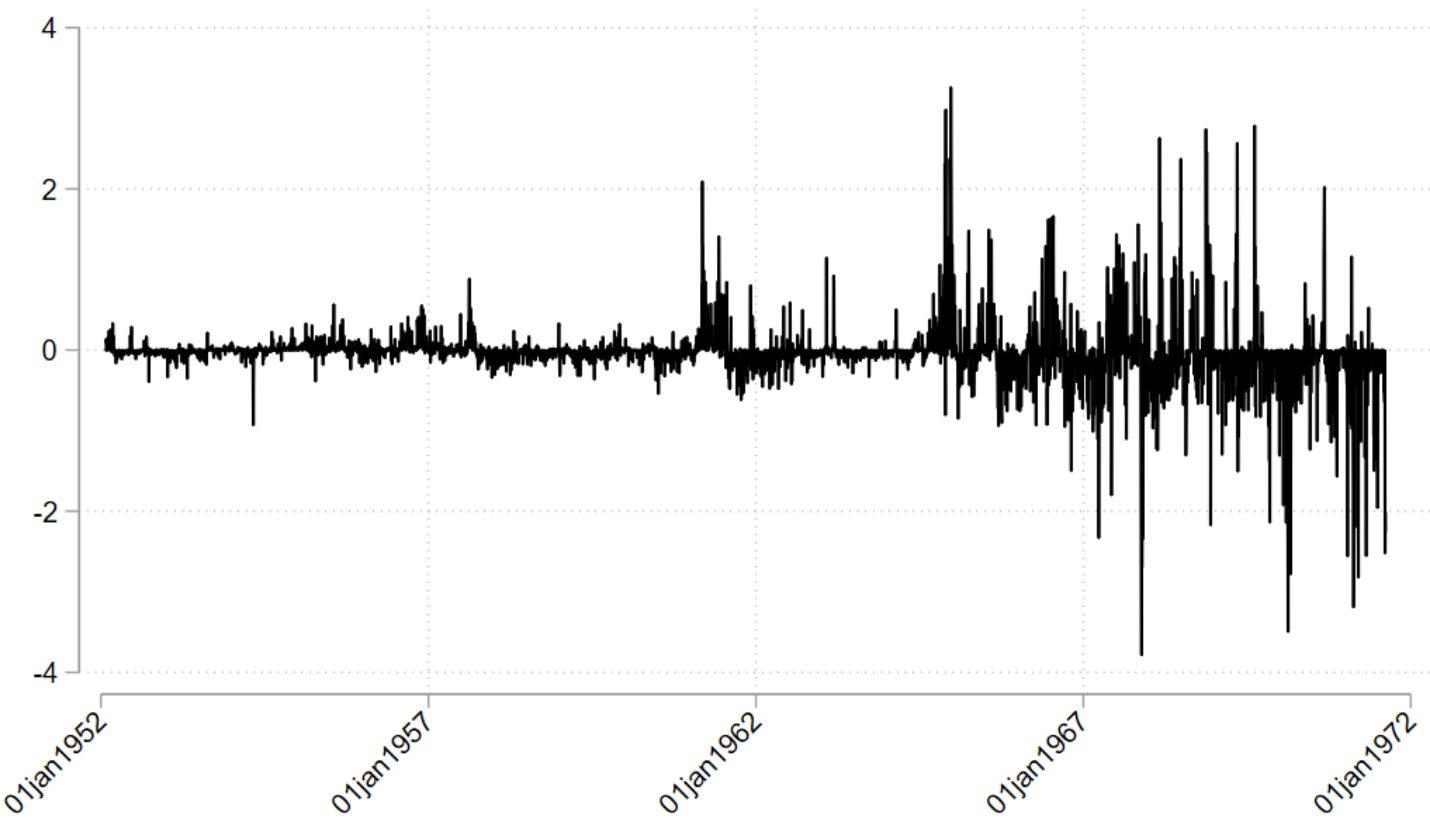

Omits three outliers of $>10 \%$ surrounding Nov. 1967 Devaluation

Figure 2: Intervention over time, deflated by UK M0. Positive values indicate sales of dollars by the Bank of England, understood as attempts to appreciate the pound vis-a-vis the dollar. This is the key right-hand-side variable in all our regressions below. See text for source. 


\section{Online Appendices}

\section{A Robustness Checks}

This appendix reports three sets of robustness checks to the paper's main IV results: adding controls, using the lagged level of the exchange rate as an instrument instead of the signed, squared, lagged distance from target, and measuring intervention $Q_{t}$ using dollar sales (instead of converting to pounds and scaling by UK M0).

\section{A.1 Adding Controls to IV Regressions}

A simple portfolio balance channel model, outlined in Section C, suggests the following controls: let $r_{t}\left(r_{t}^{*}\right)$ be the interest rate on riskless pound (dollar) bonds and let $h$ be their maturity, then the exchange rate is given by

$$
\ln e_{t}-\ln e_{t-1}=\beta_{0}+\beta_{1} Q_{t}+\beta_{2} \Delta E_{t}\left[\ln e_{t+h}\right]+\beta_{3} \Delta r_{t}+\beta_{4} \Delta r_{t}^{*}+X_{t}+\mu_{t},
$$

where $\beta_{3}$ is negative, $\beta_{4}$ is positive, and the coefficient on the $h$-period forecast revision $\beta_{2}$ is unity in theory. In practice, we use futures markets to compute forecast revisions and changes in policy rates in both countries for $r_{t}$ and $r_{t}^{*}$; the vector $X_{t}$ includes other interest rate controls, in addition to two lags of the dependent variable, as well as day-ofweek, month and year dummies. ${ }^{13}$ Including controls will change our estimate for $\beta_{1}$ if the controls are correlated with intervention $Q_{t}$ (i.e. if they belong in the true "policy rule" for intervention) and the included controls are correlated with exchange rate growth, as suggested by the model.

Table 4 demonstrates that regardless of the sample period, our IV approach flips the sign of the OLS regression and yields a precise estimate of the effect of sterilized intervention within the two standard error bands of the Table 2 results: with the full

\footnotetext{
${ }^{13}$ The full list of additional controls, not shown in Table 4, is the change in US 3-month treasury rates (available at a daily frequency) and the change in Treasury Bill Rates (available monthly). The additional UK controls include changes in consol yields, commercial paper rates, and UK M0, all available at a monthly frequency.
} 
sample, a sale of dollars/purchase of pounds equivalent to $1 \%$ of UK M0 would cause a four basis point appreciation of the pound. To give a sense of magnitude, a $1 \%$ intervention would be a large but far from abnormal daily intervention (see Figure 2 and Table 1), and the median daily change in the exchange rate (in absolute value) is 2.2 basis points in our sample. Thus, our results are consistent with the view that sterilized foreign exchange intervention was a useful tool for managing daily fluctuations. 
Table 4: Effect of Intervention on the Change in the Exchange Rate by Subsample [1952-1971]

\begin{tabular}{|c|c|c|c|c|c|c|}
\hline & \multirow{3}{*}{$\frac{\text { OLS }}{(1)}$} & \multicolumn{5}{|c|}{ IV: Distance } \\
\hline & & $(2)$ & (3) & (4) & (5) & (6) \\
\hline & & Full Sample & Pre-Devaluation & Post-Devaluation & Drop Nov. '67 & After 1958 \\
\hline Intervention & $\begin{array}{l}0.01^{*} \\
(0.00)\end{array}$ & $\begin{array}{c}-0.04^{* * *} \\
(0.01)\end{array}$ & $\begin{array}{c}-0.02^{* *} \\
(0.01)\end{array}$ & $\begin{array}{c}-0.07^{* *} \\
(0.02)\end{array}$ & $\begin{array}{c}-0.05^{* * *} \\
(0.01)\end{array}$ & $\begin{array}{c}-0.04^{* * *} \\
(0.01)\end{array}$ \\
\hline L.FX Growth & $\begin{array}{c}-0.12^{* *} \\
(0.04)\end{array}$ & $\begin{array}{l}-0.07 \\
(0.04)\end{array}$ & $\begin{array}{l}-0.02 \\
(0.02)\end{array}$ & $\begin{array}{l}-0.09 \\
(0.07)\end{array}$ & $\begin{array}{l}-0.06 \\
(0.04)\end{array}$ & $\begin{array}{l}-0.09^{*} \\
(0.04)\end{array}$ \\
\hline L2.FX Growth & $\begin{array}{c}-0.07^{* * *} \\
(0.02)\end{array}$ & $\begin{array}{l}-0.05^{*} \\
(0.02)\end{array}$ & $\begin{array}{l}-0.00 \\
(0.01)\end{array}$ & $\begin{array}{l}-0.06 \\
(0.04)\end{array}$ & $\begin{array}{l}-0.04 \\
(0.02)\end{array}$ & $\begin{array}{l}-0.05^{*} \\
(0.03)\end{array}$ \\
\hline Change in US Policy Rate & $\begin{array}{l}0.01^{* *} \\
(0.00)\end{array}$ & $\begin{array}{l}0.01^{* *} \\
(0.00)\end{array}$ & $\begin{array}{c}0.00 \\
(0.00)\end{array}$ & $\begin{array}{c}0.01 \\
(0.00)\end{array}$ & $\begin{array}{l}0.01^{* *} \\
(0.00)\end{array}$ & $\begin{array}{l}0.01^{* *} \\
(0.00)\end{array}$ \\
\hline Change in UK Policy Rate & $\begin{array}{c}-0.05^{* * *} \\
(0.00)\end{array}$ & $\begin{array}{c}-0.05^{* * *} \\
(0.01)\end{array}$ & $\begin{array}{c}-0.05^{* * *} \\
(0.01)\end{array}$ & $\begin{array}{c}-0.07^{* *} \\
(0.02)\end{array}$ & $\begin{array}{c}-0.05^{* * *} \\
(0.01)\end{array}$ & $\begin{array}{c}-0.06^{* * *} \\
(0.01)\end{array}$ \\
\hline 1-mo. Exp. Revision & $\begin{array}{c}0.59^{* * *} \\
(0.05)\end{array}$ & $\begin{array}{c}0.64^{* * *} \\
(0.05)\end{array}$ & $\begin{array}{c}0.82^{* * *} \\
(0.03)\end{array}$ & $\begin{array}{c}0.56^{* * *} \\
(0.08)\end{array}$ & $\begin{array}{c}0.65^{* * *} \\
(0.05)\end{array}$ & $\begin{array}{c}0.62^{* * *} \\
(0.06)\end{array}$ \\
\hline Observations & 4227 & 4227 & 3322 & 905 & 4209 & 3105 \\
\hline
\end{tabular}

Notes: Heteroskedasticity-robust standard errors in parentheses. The dependent variable is the log growth in the value of the dollar relative to the pound, and "Intervention" is the daily quantity of dollar sales by the Bank of England (divided by UK M0) undertaken to appreciate the pound. We also present point estimates for two lags of the dependent variable, changes in both the UK "Bank Rate" and the effective Federal Funds rate, and one month ahead expectation revisions read from futures markets. The IV results are estimated over several subsamples, including one which drops the entire month of the devaluation (November of 1967), and another which keeps only the period after an important liberalization in UK capital markets in 1958 when current account convertibility as a result of the European Monetary Agreement. While the capital account was still not completely liberated, the policy meant much larger capital flows in and out of the UK. Therefore, we separate this period in a sub-sample. All regressions include day-of-week, month and year dummies, as well as additional interest rate controls described in the text, and drop the first trading day after the November 1967 devaluation.

Stars indicate: ${ }^{*} p<0.05,{ }^{* *} p<0.01$, and ${ }^{* * *} p<0.001$ 


\section{A.2 Using the Lagged Level of the Exchange Rate As an In- strument}

The distance instrument used in the paper is $Z_{t} \equiv\left(\ln e_{t-1}-\ln e_{t-1}^{\text {target }}\right)^{2} \times \operatorname{sign}\left(\ln e_{t-1}-\right.$

$\ln e_{t-1}^{\text {target }}$ ), where the target is time-varying only because of the devaluation in sample. We motivated this instrument by arguing that if yesterday's market closed far from the target, then regardless of today's developments the dealers may be more aggressive in intervening. In practice, the variation in this instrument comes from changes in the lagged, $\log$ level of the exchange rate, $\ln e_{t-1}$, which is why we frame discussion of e.g. the exclusion restriction in these terms.

This section of the Online Appendix demonstrates that using the lagged, log level of the exchange rate alone as an instrument yields very similar results to those obtained with our "Distance" instrument. Table 5 reports estimates of our benchmark regression without controls, estimated over the pre-devaluation and post-devaluation periods as well as the entire sample. When using the whole sample, it is important to allow the effect of the level to vary across the devaluation and concomittant change in the exchange rate target in 1967 (since it is really the distance from target that influences the dealers' decisionmaking). Table 6 reports the first stage, which accords with intuition, and finally Table 7 reports results adding controls motivated by the model in Online Appendix C. The results are quite similar. The lagged, signed, squared distance from target instrument remains our headline result because it has a stronger first-stage, consistent with the idea that the dealers respond more aggressively when the exchange rate is further from target. 
Table 5: Effect of Intervention on the Change in the Exchange Rate [1952-1971]

\begin{tabular}{ccccccc}
\hline & $(1)$ & $(2)$ & $(3)$ & $(4)$ & $(5)$ & $(6)$ \\
& OLS & OLS (Pre) & OLS (Post) & IV: Level & IV: Level (Pre) & IV: Level (Post) \\
\hline Intervention & $0.02^{* * *}$ & $0.02^{*}$ & $0.03^{* * *}$ & $-0.07^{* * *}$ & $-0.05^{* * *}$ & $-0.12^{* *}$ \\
& $(0.01)$ & $(0.01)$ & $(0.00)$ & $(0.02)$ & $(0.01)$ & $(0.04)$ \\
\hline Observations & 5244 & 4278 & 966 & 5244 & 4278 & 966 \\
& & & & & \\
\hline
\end{tabular}

Notes: Heteroskedasticity-robust standard errors in parentheses. The dependent variable is the log growth in the value of the dollar relative to the pound, and "Intervention" is the daily quantity of dollar sales by the Bank of England (divided by UK M0) undertaken to appreciate the pound. Columns (1)-(3) present OLS estimates for the whole sample (1) and two sub-periods: pre-devaluation (2) and post-devaluation (3). The IV results using the lagged, log level of the exchange rate are similarly divided and imply that an intervention equivalent to $1 \%$ of UK M0 appreciates the pound by between 5 - 12 basis points, depending on the sample period. All regressions include day-of-week, month and year dummies and drop the first trading day after the November 1967 devaluation.

Stars indicate: ${ }^{*} p<0.05,{ }^{* *} p<0.01$, and ${ }^{* * *} p<0.001$

Table 6: First Stage Regressions: Effect on Intervention (Dollar Sales)

\begin{tabular}{lccc}
\hline & $(1)$ & $(2)$ & $(3)$ \\
& Level & Level (Pre) & Level (Post) \\
\hline Logged, Lagged FX Lvl. & $0.18^{* * *}$ & $0.14^{* * *}$ & $0.32^{* * *}$ \\
& $(0.02)$ & $(0.02)$ & $(0.05)$ \\
Logged, Lagged FX Lvl (after Devaluation). & $0.03^{* * *}$ & & \\
& $(0.00)$ & & \\
Constant & $19.02^{* * *}$ & $14.38^{* * *}$ & $27.75^{* * *}$ \\
& $(1.78)$ & $(1.71)$ & $(3.97)$ \\
\hline Observations & 5244 & 4278 & 966 \\
$R^{2}$ & 0.071 & 0.029 & 0.077 \\
F & 74.66 & 71.00 & 49.37 \\
& & & \\
\hline
\end{tabular}

Notes: Heteroskedasticity-robust standard errors in parentheses. The dependent variable is the daily quantity of intervention (measured as dollar sales divided by UK M0). The signs confirm the economic intuition underlying the relevance assumption of each approach: when the lagged level is high, the pound is weak relative to target and the Bank of England sells dollars to strengthen it. All regressions drop the first trading day after the November 1967 devaluation.

Stars indicate: ${ }^{*} p<0.05,{ }^{* *} p<0.01$, and ${ }^{* * *} p<0.001$ 
Table 7: Effect of Intervention on the Change in the Exchange Rate [1952-1971]

\begin{tabular}{|c|c|c|c|c|}
\hline & \multirow{2}{*}{$\frac{\text { OLS }}{(1)}$} & \multicolumn{3}{|c|}{ IV: Level } \\
\hline & & $\begin{array}{c}(2) \\
\text { Full Sample }\end{array}$ & $\begin{array}{c}(3) \\
\text { Pre Dep. }\end{array}$ & $\begin{array}{c}(4) \\
\text { Post Dep. }\end{array}$ \\
\hline Intervention & $\begin{array}{l}0.01^{*} \\
(0.00)\end{array}$ & $\begin{array}{c}-0.03^{* * *} \\
(0.01)\end{array}$ & $\begin{array}{l}-0.02^{*} \\
(0.01)\end{array}$ & $\begin{array}{c}-0.05^{* *} \\
(0.02)\end{array}$ \\
\hline L.FX Growth & $\begin{array}{c}-0.12^{* *} \\
(0.04)\end{array}$ & $\begin{array}{l}-0.08^{*} \\
(0.04)\end{array}$ & $\begin{array}{l}-0.03 \\
(0.02)\end{array}$ & $\begin{array}{l}-0.12 \\
(0.07)\end{array}$ \\
\hline L2.FX Growth & $\begin{array}{c}-0.07^{* * *} \\
(0.02)\end{array}$ & $\begin{array}{l}-0.05^{*} \\
(0.02)\end{array}$ & $\begin{array}{l}-0.01 \\
(0.01)\end{array}$ & $\begin{array}{l}-0.08^{*} \\
(0.04)\end{array}$ \\
\hline Change in US Policy Rate & $\begin{array}{l}0.01^{* *} \\
(0.00)\end{array}$ & $\begin{array}{l}0.01^{* *} \\
(0.00)\end{array}$ & $\begin{array}{c}0.00 \\
(0.00)\end{array}$ & $\begin{array}{l}0.01^{*} \\
(0.00)\end{array}$ \\
\hline Change in UK Policy Rate & $\begin{array}{c}-0.05^{* * *} \\
(0.00)\end{array}$ & $\begin{array}{c}-0.05^{* * *} \\
(0.01)\end{array}$ & $\begin{array}{c}-0.05^{* * *} \\
(0.01)\end{array}$ & $\begin{array}{c}-0.06^{* *} \\
(0.02)\end{array}$ \\
\hline 1-mo. Exp. Revision & $\begin{array}{c}0.59^{* * *} \\
(0.05)\end{array}$ & $\begin{array}{c}0.63^{* * *} \\
(0.05)\end{array}$ & $\begin{array}{c}0.81^{* * *} \\
(0.03)\end{array}$ & $\begin{array}{c}0.54^{* * *} \\
(0.08)\end{array}$ \\
\hline Observations & 4227 & 4227 & 3322 & 905 \\
\hline
\end{tabular}

Notes: Heteroskedasticity-robust standard errors in parentheses. The dependent variable is the log growth in the value of the dollar relative to the pound, and "Intervention" is the daily quantity of dollar sales by the Bank of England (divided by UK M0) undertaken to appreciate the pound. We also present point estimates for two lags of the dependent variable, changes in both the UK "Bank Rate" and the effective Federal Funds rate, and one month ahead expectation revisions read from futures markets. The IV results are estimated over the full sample (2) and two others: pre-devaluation (3) and post-devaluation (4). All regressions include day-of-week, month and year dummies, as well as additional interest rate controls described in the text, and drop the first trading day after the November 1967 devaluation.

Stars indicate: ${ }^{*} p<0.05,{ }^{* *} p<0.01$, and ${ }^{* * *} p<0.001$ 


\section{A.3 Results Measuring Intervention Using Dollar Sales}

In the paper we express interventions as a percentage of the money supply. Here we re-estimate our main IV using dollar amounts of intervention instead. This allows us to compare our results to the literature which estimates the effects of intervention measured this way. The main results are in Table 8 and Table 9 below. Specifically, we estimate $\beta_{1}$ in

$$
\left(\ln e_{t}-\ln e_{t-1}\right) \times 100=\beta_{0}+\beta_{1}\left(\text { Dollar Sales in Millions of } \mathrm{USD}_{t}\right)+\epsilon_{t}
$$

using the same instrument and sample periods, but without converting dollar sales into pounds using the exchange rate target and deflating by UK M0. The results demonstrate that the transformation does not change the results beyond scaling the size of the estimated coefficient. ${ }^{14}$ Given the IV point estimate in column 2, a sale of $\$ 10 \mathrm{mn}$ USD would appreciate the pound by 1.2 basis points, and a sale of $\$ 1$ bn USD would appreciate the pound by 1.2 percentage points. This is quite close to other estimates found in the literature: Arango-Lozano, Menkhoff, Rodríguez-Novoa, and Villamizar-Villegas (2020) report an average effect of one percentage point in a meta study of 74 papers.

\footnotetext{
${ }^{14}$ To see why, note that since M0 is measured monthly and the exchange rate target is constant except for the devaluation, in practice most of the variation in $Q_{t}=\frac{\left(\text { Dollar Sales in Millions of } \mathrm{USD}_{t}\right) \times e_{t}^{\text {target }}}{\text { UK M0 in the previous month }}$ comes from dollar sales, and $\operatorname{corr}\left(Q_{t}\right.$, Dollar Sales in Millions of $\left.\mathrm{USD}_{t}\right)=0.995$
} 
Table 8: Effect of Intervention on the Change in the Exchange Rate by Subsample [1952-1971]

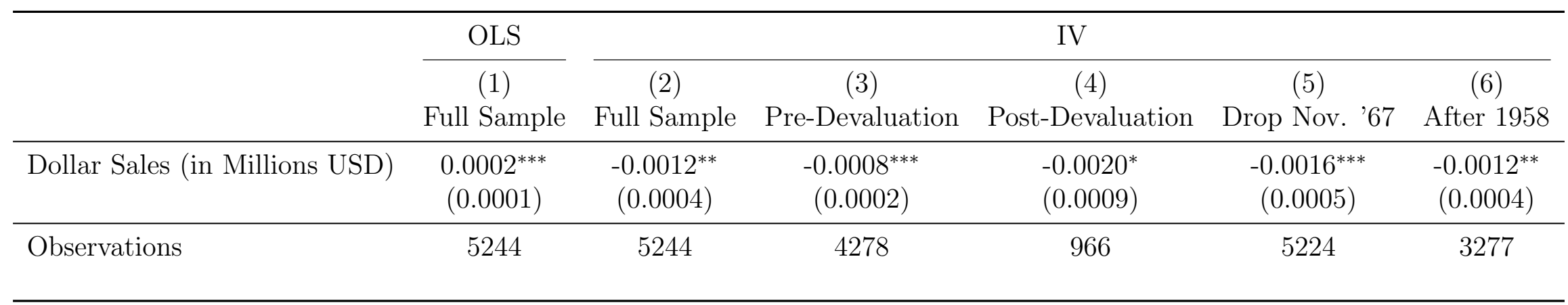

Notes: Heteroskedasticity-robust standard errors in parentheses. The dependent variable is the percentage increase in the value of the dollar relative to the pound, and "Intervention" is the daily quantity of dollar sales by the Bank of England (in millions of USD) undertaken to appreciate the pound. Columns (1) and (2) present OLS and IV estimates of the effects of intervention, demonstrating the bias in OLS and suggesting that a sale of \$1mn USD appreciates the pound by 0.12 basis points. Columns (3)-(6) present IV estimates for subsamples, where (5) drops the entire month of the devaluation (November of 1967) and (6) keeps only the period after an important liberalization in UK capital markets in 1958 when current account convertibility was restored as a result of the European

Monetary Agreement. All regressions include day-of-week, month and year dummies and drop the first trading day after the November 1967 devaluation.

Stars indicate: ${ }^{*} p<0.05,{ }^{* *} p<0.01$, and ${ }^{* * *} p<0.001$

Table 9: First Stage Regressions: Effect on Intervention (Dollar Sales) by Subsample

\begin{tabular}{lccccc}
\hline & $(1)$ & $(2)$ & $(3)$ & $(4)$ & $(5)$ \\
& Full Sample & Pre-Devaluation & Post-Devaluation & Drop Nov. '67 & After 1958 \\
\hline Lagged, Squared Distance from Target & $28.25^{* * *}$ & $19.66^{* * *}$ & $46.25^{* * *}$ & $23.99^{* * *}$ & $43.62^{* * *}$ \\
& $(3.26)$ & $(3.17)$ & $(6.79)$ & $(2.63)$ & $(5.49)$ \\
Constant & $-3.02^{* * *}$ & -0.19 & $-16.45^{* * *}$ & $-3.15^{* * *}$ & $-5.31^{* * *}$ \\
& $(0.46)$ & $(0.44)$ & $(1.62)$ & $(0.38)$ & $(0.71)$ \\
\hline Observations & 5244 & 4278 & 966 & 5224 & 3277 \\
$R^{2}$ & 0.036 & 0.019 & 0.090 & 0.036 & 0.050 \\
F & 75.12 & 38.42 & 46.43 & 83.03 & 63.02 \\
& & & & & \\
\hline
\end{tabular}

Notes: Heteroskedasticity-robust standard errors in parentheses. The dependent variable is the daily quantity of intervention (measured as dollar sales in millions of USD). The signs confirm the economic intuition underlying the relevance assumption: when the lagged distance from target instrument is positive, the pound is "too weak" relative to target and the Bank of England acts to strengthen it. All regressions drop the first trading day after the November 1967 devaluation. Stars indicate: ${ }^{*} p<0.05,{ }^{* *} p<0.01$, and ${ }^{* * *} p<0.001$ 


\section{B Treating Holiday-Driven Deviations from a "Pol- icy Rule" as Shocks to Intervention}

This section estimates a policy rule for central bank intervention based on non-holiday trading days, and uses this rule to calculate a counterfactual for the quantity of intervention that would have occurred on each holiday if the bank had been open as normal. Similarly, we estimate an exchange rate forecasting equation on non-holiday trading days and use this to create a counterfactual for exchange rate growth. Then we can regress the deviation of the exchange rate from its counterfactual on the deviation of intervention from its counterfactual and obtain an estimate of the effect of intervention.

We restrict our attention to holidays because we know on these days that the deviation from the policy rule was due to the bank being closed, and thus unrelated to developments in world currency markets. Specifically, we restrict attention to the deviations that occur on UK-specific holidays, during which the Bank of England was closed (and rarely intervened) while the pound continued to trade in New York, Zurich, and other world currency markets. ${ }^{15}$ For example, throughout our sample the last Monday of August is a secular holiday called the "Late Summer Bank Holiday" where all British markets and banks close while the rest of world traded as usual. We also include a second secular bank holiday in the winter and Good Friday in addition to Easter Monday. The results are consistent with our earlier IV results (of the same sign and magnitude) despite relying on a very different identification assumption.

Formally, we report point estimates from the following regression: denote $\hat{Q}_{t}^{i}$ as predicted intervention using some policy rule $i$ (which we will discuss below). Similarly, let $\hat{e}_{t}^{i}$ be a forecast for the exchange rate. Then we estimate the following $\beta^{i}$ via OLS:

$$
\underbrace{\left(\ln e_{t}-\ln e_{t-1}\right)-\left(\ln \hat{e}_{t}^{i}-\ln e_{t-1}\right)}_{\begin{array}{c}
\text { Forecast Error for } \\
\text { the Growth in } e
\end{array}}=\beta_{0}^{i}+\beta^{i} \times \underbrace{\left(Q_{t}-\hat{Q}_{t}^{i}\right)}_{\begin{array}{c}
\text { Deviation from } \\
\text { the Policy Rule } i
\end{array}}+\gamma_{t}^{i}
$$

\footnotetext{
${ }^{15}$ As discussed in Section 2, while the Bank of England's dealers could call and request that other central banks intervene in offshore markets during holidays, in practice they rarely did so, as they were not in the office: intervention $Q_{t}$ is zero on approximately $90 \%$ of our holidays, and the $10 \%$ of holidays with non-zero values are not driving our results (dropping them leaves point estimates unchanged).
} 
where $\beta_{0}^{i}$ is a constant, $\gamma_{t}^{i}$ is an error term, and we can interpret $\beta^{i}$ as the effect of intervention, which has the same economic interpretation and units as the coefficient estimated in our IV regressions above. ${ }^{16}$

In practice, our forecasting procedure is as follows: we use adaptive lasso to choose the policy rule from up to ten lags of the dependent variables and ten lags of all included and excluded instruments used above, in addition to various dummies and time trends. We use adaptive lasso as recent evidence suggests it performs well in time series contexts (Medeiros and Mendes, 2016).

We use lasso because simple rules do not predict either exchange rates or intervention well, and complicated rules require discipline, as it is not a priori obvious what belongs in the policy rule. ${ }^{17}$ Unlike with conventional monetary policy, where the arguments of the central bank's policy rule are well understood, contemporaries were vague on the determinants of day-to-day operations even in their secret, internal communications. As Harry Siepmann unhelpfully wrote in 1936, in a section labeled "tactics":

The tactics and management of the EEA naturally attract a good deal of attention and comment, but the fact is that the technique of day-to-day operations is not susceptible of much development or variation. Once the objectives have been set by policy, the question of method is a matter for practical judgment and opportunism, which necessarily depends upon the state of the market. In the press and elsewhere an attempt is occasionally made to propound some kind of theory of management... All such hypothetical arguments have the advantage that, by their very nature, they cannot be disproved.

While it is possible that operations could have become more systematic in the period studied here, we conclude that an atheoretic approach has some appeal. Finally, using

\footnotetext{
${ }^{16}$ Note that using a forecast error on the left hand side is formally almost identical to simply including the variables chosen by the adaptive lasso as controls on the right hand side.

${ }^{17}$ To see why simple policy rules have little power, note the first stage of our IV regression in Table 3 has an R-squared of .04; fitting parsimonious such simple rules would leave us with little power. Use of Lasso allows us to make nontrivial predictions and raise the R-squared values without concerns of overfitting (the Lasso models described below are capable of explaining 20-25\% of the variance in-sample for intervention). Note that this approach benefits heavily from the fact that in our setting the central bank is intervening almost every day, so that a policy rule can be meaningfully estimated.
} 
adaptive lasso to estimate the policy rule (instead of OLS) mitigates concerns of overfitting. If we overfit, this will effectively add "noise" to our policy shock measure, biasing estimates of $\beta^{i}$ toward zero.

Note that even having chosen adaptive lasso as our estimator, we still have some freedom over its implementation. Accordingly, we present results from three different forecasting procedures that yield distinct models, labelled according to the information criterion involved in the implementation: either AIC (Akaike Information Criterion), BIC (Bayesian Information Criterion) or Extended BIC (EBIC).$^{18}$ In practice it is not clear which model we should favor in our context, which is why we present multiple; see Online Appendix B.1 below for details. The results of estimating $\beta^{i}$ in equation (3) via OLS given the different forecasts from the two models are largely consistent, and presented in Table 10. Note that the coefficients on intervention have the same interpretation as previous tables, and we thus compare them directly.

The first three columns of Table 10 present results for all non-holiday trading days, suggesting that a sale of dollars equivalent to $1 \%$ of UK M0 actually depreciates the pound by 3 basis points. We include these columns to show that use of a policy rule alone is not helpful in achieving identification and simply recovers the positive OLS estimates in the first columns of Table 2 and Table 4. As the Bank of England official Harry Siepmann stated above, day-to-day operations respond in real time to changes in market conditions, meaning that deviations from the rule on the right-hand-side in our setting are generally endogenous to any shocks driving exchange rate movements.

Columns (4) to (6) restrict our sample to holidays, when we know deviation from the policy rule is driven by the closure of the Bank of England and not current developments in financial markets. Here we obtain results of the same sign and magnitude as the IV results in Table 4, suggesting that a sale of dollars equivalent to 1\% of UK M0 appreciates the pound by 6-7 basis points, depending on the specification. Finally, as a robustness check, Table 11 demonstrates the robustness of point estimates for intervention using holidays to the choice of subsample, obtaining similar results.

\footnotetext{
${ }^{18} \mathrm{~A}$ fourth option, the corrected AIC or AICc, yields similar results as for the AIC and is thus omitted.
} 
Table 10: Effects of Sterilized Intervention on the Log Growth in the Value of the Dollar using Policy Rules and Forecasts Estimated via Adaptive Lasso: Results by Choice of Information Criterion

\begin{tabular}{lccccccc}
\hline & \multicolumn{3}{c}{ All Dates } & & \multicolumn{3}{c}{ Holidays } \\
\cline { 2 - 4 } \cline { 6 - 8 } & $(1)$ & $(2)$ & $(3)$ & & $(4)$ & $(5)$ & $(6)$ \\
& BIC & EBIC & AIC & & BIC & EBIC & AIC \\
\hline Intervention: BIC & $0.03^{* * *}$ & & & $-0.07^{*}$ & & \\
& $(0.01)$ & & & $(0.03)$ & & \\
Intervention: EBIC & & $0.03^{* * *}$ & & & $-0.06^{+}$ & \\
& & $(0.01)$ & & & $(0.03)$ & \\
Intervention: AIC & & & $0.03^{* *}$ & & & $-0.07^{*}$ \\
& & & $(0.01)$ & & & $0.03)$ \\
\hline Observations & 3453 & 3849 & 3170 & 41 & 52 & 38 \\
$R^{2}$ & 0.047 & 0.051 & 0.045 & 0.088 & 0.052 & 0.117 \\
& & & & & & & \\
\hline
\end{tabular}

Notes: Heteroskedasticity-robust standard errors in parentheses. The dependent variable is the log growth in the value of the dollar relative to the pound, and "Intervention" is the daily quantity of dollar sales by the Bank of England (divided by UK M0) undertaken to appreciate the pound, each given as a deviation from a forecast computed using the adaptive lasso and either the BIC, EBIC or AIC as an information criterion (see Online Appendix B.1; results with the AICc are identical to the AIC in our context and omitted). The table compares the results using just holiday dates to the results using all dates in columns (1)-(3). With all dates we replicate the OLS results, while with holidays we recover results consistent with the IV columns in Table 4. Note we are missing some holidays because forecasts could not be computed (due to missing data) and that this explains the smaller number of observations when using less parsimonious models (e.g. the AIC selected model).

Superscripts indicate: ${ }^{+} p<0.10,{ }^{*} p<0.05,{ }^{* *} p<0.01$, and ${ }^{* * *} p<0.001$ 
Table 11: Effects of Sterilized Intervention on the Log Growth in the Value of the Dollar using Policy Rules and Forecasts Estimated via Adaptive Lasso: Results by Choice of Information Criterion and Subsample

\begin{tabular}{|c|c|c|c|c|c|c|c|c|c|}
\hline & \multicolumn{9}{|c|}{ Results Using Holidays: } \\
\hline & \multicolumn{3}{|c|}{ Pre-Devaluation } & \multicolumn{3}{|c|}{ After 1958} & \multicolumn{3}{|c|}{ Pre-Devaluation, After 1958} \\
\hline & $\begin{array}{c}(1) \\
\text { BIC }\end{array}$ & $\begin{array}{c}(2) \\
\text { EBIC }\end{array}$ & $\begin{array}{c}(3) \\
\text { AIC }\end{array}$ & $\begin{array}{c}(4) \\
\text { BIC }\end{array}$ & $\begin{array}{c}(5) \\
\mathrm{EBIC}\end{array}$ & $\begin{array}{c}(6) \\
\text { AIC }\end{array}$ & $\begin{array}{l}(7) \\
\text { BIC }\end{array}$ & $\begin{array}{c}(8) \\
\text { EBIC }\end{array}$ & $\begin{array}{c}(9) \\
\text { AIC }\end{array}$ \\
\hline Intervention: $\mathrm{BIC}$ & $\begin{array}{l}-0.08^{+} \\
(0.05)\end{array}$ & & & $\begin{array}{c}-0.05^{* * *} \\
(0.01)\end{array}$ & & & $\begin{array}{c}-0.04^{* * *} \\
(0.01)\end{array}$ & & \\
\hline Intervention: EBIC & & $\begin{array}{r}-0.09^{+} \\
(0.05)\end{array}$ & & & $\begin{array}{r}-0.03^{+} \\
(0.02)\end{array}$ & & & $\begin{array}{c}-0.06^{* *} \\
(0.02)\end{array}$ & \\
\hline Intervention: AIC & & & $\begin{array}{r}-0.08^{+} \\
(0.05)\end{array}$ & & & $\begin{array}{c}-0.04^{* *} \\
(0.01)\end{array}$ & & & $\begin{array}{l}-0.04^{*} \\
(0.01)\end{array}$ \\
\hline $\begin{array}{l}\text { Observations } \\
R^{2}\end{array}$ & $\begin{array}{c}30 \\
0.074\end{array}$ & $\begin{array}{c}38 \\
0.096\end{array}$ & $\begin{array}{c}27 \\
0.111\end{array}$ & $\begin{array}{c}33 \\
0.189\end{array}$ & $\begin{array}{c}39 \\
0.058\end{array}$ & $\begin{array}{c}32 \\
0.156\end{array}$ & $\begin{array}{c}22 \\
0.206\end{array}$ & $\begin{array}{c}25 \\
0.196\end{array}$ & $\begin{array}{c}21 \\
0.166\end{array}$ \\
\hline
\end{tabular}

Notes: Heteroskedasticity-robust standard errors in parentheses. The dependent variable is the log growth in the value of the dollar relative to the pound, and "Intervention" is the daily quantity of dollar sales by the Bank of England (divided by UK M0) undertaken to appreciate the pound, each given as a deviation from a forecast computed using the adaptive lasso and either the BIC, EBIC or AIC as an information criterion (see online appendix B.1 for details on computation; results with the AICc are identical to the AIC in our context and are omitted). The table demonstrates the robustness of the results in Table 10 to the choice of subsample. Note we are missing some holidays because forecasts could not be computed (due to missing data) and that this explains the smaller number of observations when using less parsimonious models (e.g. the AIC selected model). The small number of holidays prevents meaningful estimation over the post-devaluation sample, so these results are omitted.

Superscripts indicate: ${ }^{+} p<0.10,{ }^{*} p<0.05,{ }^{* *} p<0.01$, and ${ }^{* * *} p<0.001$ 


\section{B.1 Adaptive Lasso Implementation}

We use the lassopack package in Stata (version 1.4.1) provided by Ahrens, Hansen, and Schaffer (2020) to implement adaptive lasso, using default values for implementation, and note the importance of the choice of information criterion.

We allow for up to ten lags of the following: intervention as a fraction of M0, gold reserves as a fraction of M0, lagged squared distance from target (i.e. the instrument used in our earlier IV regressions), growth in the exchange rate, forecast error revisions, changes in the Bank of England policy rate and changes in the Fed Funds rate. We also allow for a linear time trend, a time trend with a break after the devaluation, a dummy for being post-devaluation, day-of-week, month and year dummies, and all of our previous interest rate controls (which were available at a monthly frequency).

Adaptive lasso is a shrinkage estimator; formally, we pick parameters $\lambda$ and $\omega_{j}$ and solve the resulting optimization problem:

$$
\hat{\boldsymbol{\beta}}=\underset{\beta}{\arg \min } \frac{1}{2 n} \sum_{i=1}^{n}\left(y_{i}-\boldsymbol{x}_{i} \boldsymbol{\beta}^{\prime}\right)^{2}+\lambda \sum_{j=1}^{p} \omega_{j}\left|\beta_{j}\right|
$$

where $y_{i}$ is either the growth in the exchange rate or intervention as a fraction of UK M0, and $x$ is a vector of $p$ potential predictors. Adaptive lasso uses a set of initial OLS estimates to pick the $\omega_{j}$, and $\lambda$ is chosen so that the resulting model minimizes a particular information criterion: either the Akaike information criterion (AIC), Bayesian information criterion (BIC), or the Extended BIC (EBIC). The BIC and EBIC yield more parsimonious models, while the AIC has a greater in-sample fit and produces more substantial forecasts. In Table 10 and Table 11 of the main text, we presented results for all three approaches. ${ }^{19}$

To obtain the coefficients shown in Table 10, we regress the forecast error for exchange rate growth on the forecast error for intervention (i.e. the deviation from the policy rule). Denote $\hat{Q}_{t}^{i}$ as predicted intervention using either the $i=B I C, A I C$ or $E B I C$ model. Similarly, let $\hat{e}_{t}^{i}$ be the forecast for the exchange rate. Then we estimate the following $\beta^{i}$

\footnotetext{
${ }^{19}$ The software package we use also produces estimates based on the corrected AIC (AICc) but in our context this delivers identical results to using the AIC.
} 
for each model via OLS:

$$
\underbrace{\left(\ln e_{t}-\ln e_{t-1}\right)-\left(\ln \hat{e}_{t}^{i}-\ln e_{t-1}\right)}_{\begin{array}{c}
\text { Forecast Error for } \\
\text { the Growth in } e
\end{array}}=\beta_{0}^{i}+\beta^{i} \times \underbrace{\left(Q_{t}-\hat{Q}_{t}^{i}\right)}_{\begin{array}{c}
\text { Deviation from } \\
\text { the Policy Rule } i
\end{array}}+\gamma_{t}^{i}
$$

where $\gamma_{t}^{i}$ is an error term. As Table 10 shows, in this step it is critical to restrict $t$ to be in the set of dates which are holidays: there, we know the deviations from the policy rule on the right-hand-side are plausibly exogenous. Note the economic interpretation of $\beta^{i}$ is similar to our IV regressions with controls and we should expect similar point estimates if both approaches are truly identifying as-good-as-random variation in $Q_{t}$.

\section{A Reduced-Form Portfolio Balance Channel Model of Sterilized Foreign Exchange Intervention ${ }^{20}$}

We use a simple model to discipline our regression specifications and choice of controls, as well as illustrate a case where the distance instrument's exclusion restriction only holds "approximately" due to the presence of mean-reverting fundamental shocks to the level of the exchange rate.

Define $e_{t}$ as the exchange rate in terms of the home currency (pounds) per unit of foreign currency (dollars), so that an increase in $e$ is a depreciation of home's currency. World demand for home (pound) bonds is determined by some function $D$ which is increasing in their excess return over foreign (dollar) bonds. Letting $R_{t}$ and $R_{t}^{*}$ denote gross interest rates on $h$-period home and foreign currency bonds,

$$
\text { World Portfolio Share of Home Bonds } \equiv \chi_{t} D\left(R_{t}-R_{t}^{*}\left(\frac{E_{t}\left[e_{t+h}\right]}{e_{t}}\right)\right) \text {. }
$$

This is a standard reduced-form model of UIP deviations. ${ }^{21}$ We assume that the log of

\footnotetext{
${ }^{20}$ This is sometimes also called the "imperfect asset substitutability" or "risk premium" channel.

${ }^{21}$ This model follows e.g. Frankel (1984), but assuming a representative investor and a more general relationship between the portfolio share and excess return. This standard model is used in undergraduate texts (e.g. Krugman, Obstfeld, and Melitz, 2015) and applied work, often with extensions (e.g. Cushman, 2007). A similar relationship also holds in microfounded models such as Gabaix and Maggiori (2015),
} 
the demand shifter $\chi_{t}$ follows an $\mathrm{AR}(1)$ process:

$$
\ln \chi_{t}=\rho \ln \chi_{t-1}+\delta_{t}
$$

where $\rho \in[0,1]$ and $\delta_{t}$ is a white noise process. We assume the supply of bonds available for the private sector to hold is given by total home (UK) government debt, denoted $B_{t}$, less central bank holdings, denoted $A_{t}$. If we let $W_{t}$ denote global wealth, the world portfolio share of home bonds must be:

$$
\text { World Portfolio Share of Home Bonds } \equiv \frac{B_{t}-A_{t}}{W_{t}}
$$

Given the supply of home currency bonds, equilibrium in the market for home debt is achieved through the exchange rate adjusting today, given gross interest rates and expectations of the exchange rate. The intuition is simple: if the expected returns on the two bonds are unchanged, their relative price must adjust when the central bank alters the supply. This is achieved through exchange rate adjustment.

Setting supply equal to demand, normalizing the financial stock variables $A_{t}, B_{t}$ and $W_{t}$ by UK M0 at time $t$ (denoting them, $a_{t}, b_{t}$, and $w_{t}$, respectively) yields

$$
\frac{b_{t}-a_{t}}{w_{t}}=\chi_{t} D\left(R_{t}-R_{t}^{*}\left(\frac{E_{t}\left[e_{t+h}\right]}{e_{t}}\right)\right)
$$

Log-linearizing around a steady state in which all variables in (4) are constant yields a framework for our regressions. Then, since we do not observe the size of the bank's balance sheet at a daily frequency, but only the changes, we first difference. In what follows, for any variable $z_{t}$, we use $z$ to denote the steady state of $z_{t}$; writing $\ln R=\ln (1+r) \approx r$, and letting $\Delta$ be one period differences over $t$, we obtain

$$
\Delta \ln e_{t}=E_{t}\left[\ln e_{t+h}\right]-E_{t-1}\left[\ln e_{t+h-1}\right]-\frac{R}{R^{*}} \Delta r_{t}+\Delta r_{t}^{*}-\frac{\varphi}{b-a} \Delta a_{t}+\epsilon_{t}
$$

who obtain a similar demand function assuming incentive-compatibility constraints prevent risk-neutral investors from arbitraging away UIP deviations. 
where $\epsilon_{t}$ collects unobserved structural errors, and $\varphi$ is a positive, uninteresting collection of steady-state values. ${ }^{22}$ The sign accords with intuition regarding sterilized foreign exchange interventions, as $\Delta a_{t}$ in this model corresponds with the sterilized intervention data collected and divided by $\mathrm{M} 0$, or $Q_{t}$ in the text. ${ }^{23}$

For the instrument to work, we need the level of the exchange rate to be uncorrelated with the changes in the structural shocks $\epsilon_{t}$. To see how mean reversion in fundamental shocks violates this, consider the case where $b_{t}$ and $w_{t}$ are constant, so that the error simplifies to

$$
\epsilon_{t} \equiv \varphi \Delta \ln \chi_{t}
$$

Since the distance instrument contains a lag of the exchange rate, it contains the shock $\chi_{t-1}$. It will generally only be orthogonal to the error term if $\Delta \ln \chi_{t}=(\rho-1) \ln \chi_{t}+\delta_{t}$ is i.i.d. which is only the case if $\rho=1$ and the demand shifter is a random walk. Thus, we note that if $\rho$ is close to one then the exclusion restriction will be almost satisfied.

This exclusion assumption was motivated by the observation that most models of the exchange rate do not out-perform a simple random walk model in out-of-sample forecasting exercises, particularly over short horizons (Meese and Rogoff, 1983; Rossi, 2013); the hope is that any mean reversion (and corresponding downward bias in our IV estimates of the effects of intervention) is small enough to be ignored. Online Appendix D explores this formally, showing through simulation that empirically-plausible levels of mean reversion are unlikely to explain the IV results obtained in the main paper alone (under the null hypothesis that intervention is not effective).

Regarding our specification with controls, we estimate the following version of the above equation:

$$
\Delta \ln e_{t}=\beta_{0}+\beta_{1} Q_{t}+\beta_{2} \Delta E_{t}\left[\ln e_{t+h}\right]+\beta_{3} \Delta r_{t}+\beta_{4} \Delta r_{t}^{*}+X_{t}+\mu_{t}
$$

\footnotetext{
${ }^{22}$ Formally, $\varphi \equiv \frac{D^{\prime}\left(R-R^{*}\right)}{D\left(R-R^{*}\right)} R^{*}$ and $\epsilon_{t} \equiv \varphi\left(\frac{b}{b-a} \Delta \ln b_{t}-\Delta \ln w_{t}-\Delta \ln \chi_{t}\right)$.

${ }^{23}$ To see the correspondence between the "dollar sales" variable $Q_{t}$ and the change in the central bank's holding of pound bonds $\Delta \ln a_{t}$, consider an example where the Bank of England (the home country) sells dollars and buys pounds. When the Bank of England buys home bonds to sterilize the intervention, $a_{t}$ increases.
} 
where $\Delta \ln A_{t}$ has been replaced by $Q_{t}$ and $X_{t}$ includes day-of-week, month and year fixed effects, two lags of the dependent variable and various interest rate controls. We use changes in one month forward rates to proxy for $\Delta E_{t}\left[\ln e_{t+h}\right]$, and policy rates in each country as our measures of $r_{t}$ and $r_{t}^{*}$. Note that from the model's perspective, ideally we would use changes in risk-free $h$-month rates, but these are not always available at daily frequencies (an exception is the US 3-month treasury rate which is available at a daily frequency from FRED). We thus also include various changes in available interest rates at monthly frequencies as described in Appendix Section E.

\section{Long-Run Mean Reversion and Identification Con-}

\section{cerns}

The exclusion assumption in our IV regressions is that the log-level of the exchange rate is not useful for forecasting its own growth rate, conditional on the (secret) interventions by the central bank. This assumption is motivated by the fact that fundamentals-based models of the exchange rate usually underperform a simple random walk without drift in out-of-sample forecasting exercises (Meese and Rogoff, 1983; Rossi, 2013). However, a large literature documents that shocks to the exchange rate may be mean-reverting to some fundamental value in the very long run. ${ }^{24}$ Could plausibly-small deviations from the random walk model, consistent with long-run mean reversion, explain our results?

To show that this is unlikely, this appendix simulates data from a model where intervention is actually ineffective (true $\beta_{1}=0$ ) but where our IV estimates will nevertheless tend to be negative because of mean reversion in the exchange rate. After running multiple simulations, we can examine the distribution of results and conclude whether or not our actual IV estimates are likely to come from such a model. We choose parameters to match key features of the data, including our observed strong first stage and positive OLS coefficient (note that since we assume $\beta_{1}=0$, replicating weakly-positive but near

\footnotetext{
${ }^{24}$ See e.g. Sweeney (2006); Bessec (2003); Taylor and Peel (2000). Murray and Papell (2002) surveyed the literature on convergence to PPP and found that deviations have a half life of 3-5 years, but argued that the appropriate range is closer to 2-20 years.
} 
zero OLS coefficients necessarily implies little bias in OLS). We conclude by noting that our actual IV estimates lie well outside the $90 \%$ range of estimates from these simulations except for cases where mean reversion is unreasonably high, suggesting that we can reject that this model of the world is behind our IV estimates. We conclude that our IV estimates suggest that intervention is effective, but caution that they may be biased downward.

First consider the simplest estimating equation from our paper, where $\ln e_{t} \equiv s_{t}$ :

$$
s_{t}-s_{t-1}=\hat{\beta}_{0}+\hat{\beta}_{1} Q_{t}+\hat{\epsilon}_{t}
$$

and where we instrumented for $Q_{t}$ with $s_{t-1}$. The results from this exercise are in Table 5 and Table 6. Assume the true model is

$$
s_{t}=\rho s_{t-1}+\beta_{1} Q_{t}+\epsilon_{t}
$$

and the policy rule for intervention is

$$
Q_{t}=\phi s_{t-1}+\epsilon_{t}+\mu_{t}
$$

where $\phi$ indicates the responsiveness to the lagged level of the exchange rate from a target; we assume the target is zero here for simplicity. The presence of $\epsilon_{t}$ reflects the fact that the central bank responds to current shocks (offsetting them if $\beta_{1}<0$ ). $\mu_{t}$ is a white noise process reflecting idiosyncratic decisions by the central bank's dealers and perhaps an imperfect knowledge of the shocks $\epsilon_{t}$.

The exclusion restriction requires that $\rho=1$, but long-run convergence to some mean suggests $\rho$ may be slightly less than one. ${ }^{25}$ This would bias the IV estimates of $\beta_{1}$ downward. However, the low levels of $\rho$ needed to quantitatively explain our results under the null hypothesis that $\beta_{1}=0$ are inconsistent with modest long-run mean reversion.

To show this, we simulate data from the data generating process given by (6) and

\footnotetext{
${ }^{25}$ Note even if $\rho=1$ and $\beta_{1}<0$, then the central bank's policy rule implies the exchange rate will not follow a random walk, but instead follow a stable $\mathrm{AR}(1)$; to see this, substitute (7) into (6).
} 
(7) where $\beta_{1}=0$ (by assumption) and $\phi=.14$ (as estimated from the pre-devaluation data). ${ }^{26}$ We choose $\epsilon_{t} \sim N(0, .05)$ to match a standard deviation of changes in the log exchange rate of .05 , and we choose $\mu_{t} \sim N(0, \sigma)$, where $\sigma=.75$ is chosen to approximate the F-statistic and $R^{2}$ of the first stage regression. ${ }^{27}$

Given these choices, and a choice for $\rho$, we simulate 500 IV estimates on samples of 5,000 trading days each, reporting the mean and $90 \%$ distribution. Figure 3 plots the average IV estimate and 90\% distribution for specific choices of $\rho \in[.9975, .9999]$ corresponding to decay rates of $0-5 \%$ at the monthly level (assuming 21 trading days in a month) or, equivalently, to shock half-lives of as little as a year for comparision to the literature on long-run convergence to PPP. Our point estimate generally lies well below the simulated results, even for large amounts of mean reversion, suggesting that mean reversion alone is unlikely to explain our IV results.

\section{E Data Sources}

For exchange rates, we rely on data collected by Accominotti et al. (2019) from the Financial Times, and patch in missing data from Global Financial Data (GFD). ${ }^{28}$ We also take one-month forward premiums from this same source, which we use to construct the forecast revision $\Delta E_{t}\left[\ln e_{t+h}\right]$ in equation (5). All other interest rate controls and UK M0 are downloaded from the Federal Reserve Economic Database (FRED), except for the UK policy rate which is taken from the Bank of England.

For our intervention variable, we deflate by the previous months UK M0. We also include the following monthly changes as controls in some specifications (with FRED series names): changes in UK M0 (MBM0UKM); changes in US Treasury Bill rates

\footnotetext{
${ }^{26}$ Calibrating the simulation using the post-devaluation sample and investigating the $\rho$ necessary to replicate those results only makes the conclusion more stark, both because our point estimate $\hat{\beta}_{1}$ is much more negative $(-0.17$ instead of -0.05$)$ and the coefficient on the first stage is larger $(\phi=.32)$, which generally improves the behavior of the IV estimator in our simulations. We thus report only the more precisely estimated pre-devaluation sample.

${ }^{27} \mathrm{~A}$ low $R^{2}$ requires $\sigma$ to be large, but results are not sensitive to this choice (we tried $\sigma \in\{.5, .75,1.0\}$ ).

${ }^{28}$ We prefer to use the Accominotti et al. (2019) data from Financial Times since it is better documented, and patch in for dates when data is missing due to e.g. bad scans of the Financial Times. In particular we also use the GFD data to obtain prices for holiday dates when the world market was still trading. In practice, on the days when they overlap, the correlation between the Financial Times data and the GFD data is effectively one.
} 


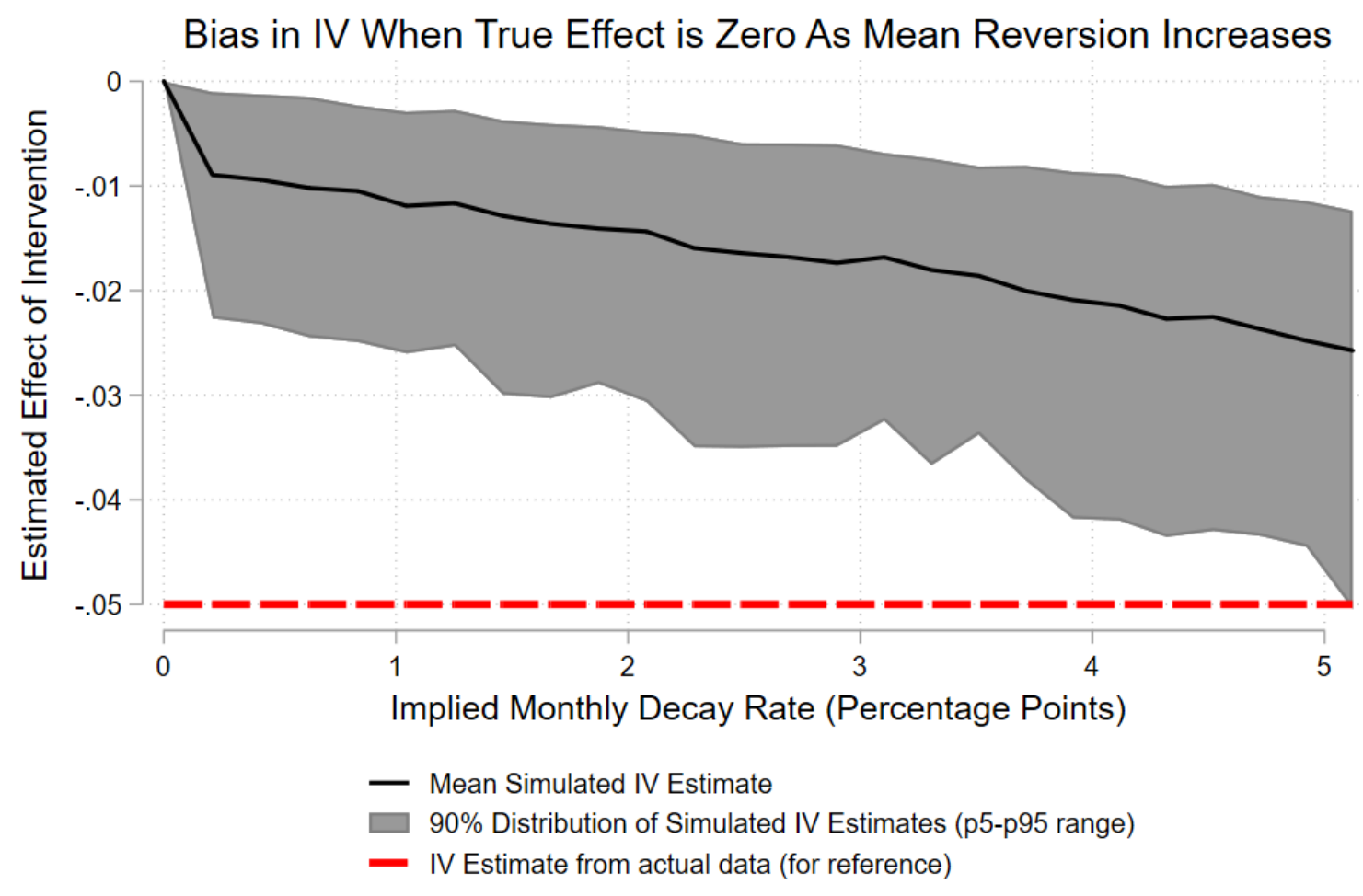

Figure 3: Bias in IV under the null hypothesis that $\beta_{1}=0$ for $\rho \in[.9975, .9999]$, which corresponds to the monthly decay rates on the horizontal axis. Note a monthly decay rate of e.g. $3 \%$ is quite large (as this implies a half life of shocks of as little as two years). 
(INTGSTUSM193N); changes in 3-month Treasuries (TB3MS); changes in UK console yields (YCLTUK); and changes in UK commercial paper rates (DRSTPUKM). For daily interest rates, changes in the Bank Rate were downloaded from the Bank of England's web site; we also included changes in the US policy rate as captured by the effective Fed Funds rate (DFF) and changes in 3-month treasury rates (DTB3), though these series only begin in 1954 .

One non-trivial data cleaning issue bears mentioning: foreign exchange markets in Europe were open on Saturdays from April 15th, 1955 to October 17th, 1964, and the Bank of England intervened over the weekend as a result. However, the Bank of England recorded its intervention for both Friday and Saturday jointly, so that we do not observe how much intervention occurred on each day. Rather than impute, we instead treat Friday and Saturday as one trading day for the purposes of estimation, and construct changes from end-of-day Thursday to end-of-day Saturday when creating our controls and non-intervention variables. All references to the number of observations made in the text account for this, counting Friday and Saturday together as one trading day instead of two.

\section{E.1 Details and Treatment of the 1967 Devaluation}

The announcement of the devaluation occured on a Saturday (November 18th, 1967) when the market was closed. We drop the first trading day after the devaluation (Tuesday, November 21st 1967). Monday was declared a "bank holiday" which is also dropped from our analysis (Forrest, 2010). ${ }^{29}$ We "drop" these days by not including them as observations in any regressions or tabulations and also set the appropriate values to missing for our regressors (so that they are not influencing our results when we take e.g. lags of the growth rate of the exchange rate). This procedure is what is meant by the line in each table caption, "All regressions include day-of-week, month and year dummies, as well as additional interest rate controls described in the text, and drop the first trading day after the November 1967 devaluation."

\footnotetext{
${ }^{29}$ Note we do not include such bank holidays in our "holidays" approach, as these closures are far from randomly assigned.
} 
Our regression specifications that drop the entirety of the month of November 1967 further ensure that the devaluation episode is not driving our results. The motivation behind this exercise is that discussion of devaluation began internally prior to November 18th (on November 16th, the Chancellor of the Exchequer recommended a devaluation to the Cabinet) and one might be skeptical that this was completely private information. However, as shown in the original results that estimated regressions over the full sample, it does not appear that including the month of November, 1967 drives our results. 